\title{
Capital account opening and economic growth-an empirical test based on systematic GMM
}

\author{
Jia Siming ${ }^{1}$ \\ ${ }^{1}$ School of economics and management, Beijing Jiaotong University, master's degree, Beijing, CHINA
}

\begin{abstract}
This paper collected panel data of 74 countries from 1990 to 2017, and based on the Chinn-It index to depict the degree of capital account opening. Under the framework of the neoclassical economic growth model, the impact of capital account opening on economic growth was empirically tested by systematic GMM. The results show that: first, taking the overall capital account openness as the explanatory variable, the coefficient of the capital account openness of the whole sample is significantly positive. Further, considering the national differences found that high income countries capital account openness coefficient is significantly positive, but in low and middle-income countries capital account openness coefficient on economic and statistical significance were not significant, indicating that high income countries made open dividends, while in low and middle-income countries and earnings in the capital account liberalization. Finally, it proposes to open the capital account sub-projects step by step, strengthen prudent supervision in the process of further opening the capital account, and improve the regulatory legal system.
\end{abstract}

\section{Introduction}

Capital account liberalization includes the abolition of cross-border capital transaction restrictions and the abolition of foreign exchange restrictions on capital transactions. The latter includes the liberalization of local and foreign exchange and the liberalization of capital transfer. Since the end of The Bretton Woods system in 1971, capitalist countries have no obligation to restrict capital flows to maintain a fixed exchange rate. International organizations such as the World Bank have also begun to emphasize the benefits of capital account opening in diversifying risks and reducing the cost of capital. However, the opening of the capital account was not smooth sailing. The outbreak of the Asian financial crisis in 1997 slowed down the opening of the capital account in many countries. International organizations such as the World Bank have also become more moderate in their attitude towards capital account opening, believing that some transactions under the capital account can be regulated. It is also in favor of re-regulating projects that have been deregulated in the face of complex and changing economic and financial conditions.

Since China formally joined the WTO in December 2001, the opening of China's capital account has been further accelerated. Until 2012, the People's Bank of China issued a research report, pointed out that China to speed up the capital account opening conditions are basically mature. Open capital account is in the process of our modernization drive must be crossed a threshold, on the other hand, under the background of our country economy the new normal, in order to achieve high quality development, improve the international voice and the internationalization of the RMB will need to be done under the condition of a more open, on May 7, 2020, the central bank issuing the "foreign institutional investors in securities and futures investment funds management stipulation" , one of the biggest changes in allowing qualified investors choose remit money currency and timing and greatly simplifies the investment income of export formalities. These policies show that China's determination to further open its capital account to the outside world has not wavered. At the same time, China is now facing a complex and severe domestic and international economic and political environment, such as the rise of anti-globalization trend in the United States. In addition, the sudden 2019-ncov has cast a shadow over the global economy. The international monetary fund predicts that the global economic growth rate will decline to $-3 \%$ in 2020. In this special period, the Federal Reserve even launched the unprecedented unlimited quantitative easing plus zero interest rate "king bomb combination". Under this background, whether to further promote the opening of capital account and the internationalization of RMB through such a time window has aroused extensive discussions in the academic world. At present, there are many debates and questions about the economic consequences of capital account opening in academic circles. Therefore, it is of practical significance to empirically examine the economic consequences of capital account opening through the latest data.

Based on the neoclassical economic growth theory, this paper constructs a model, and adopts Chinn-Ito index to describe the degree of capital account opening. It examines the economic consequences of capital account 
opening in 74 countries (regions) from 1990 to 2017, and further distinguishes the country effect. Compared with previous studies, this paper further screened the sample countries, with a longer sample period, and adopted systematic GMM method to solve the existing dynamic panel and endogeneity problem. In this paper, the existing research was supplemented: (1) the Chinn-Ito index was used in combination with the neoclassical economic growth theory to build a model to study the impact of capital account opening on economic growth.(2) combined with the latest data using GMM system to study the capital account opening effect of the country.

The rest of this paper is arranged as follows: the second part is the literature review; the third part is the empirical analysis, which describes the econometric model and data, and lists the regression results and robustness test. The fourth part is the conclusion and revelation.

\section{Literature review}

Theoretically, the influence channels of capital account opening on economic growth can be divided into two aspects, namely direct channels and indirect channels. Direct channel, according to the new classical economic growth theory, the accumulation of capital is of great contribution to economic growth, under the condition of capital account liberalization, relative to the developing and developed countries tend to have more capital, but the return on capital is relatively low, in this case, the capital will tend to one country from rich to poor, main performance in improving the investment efficiency, reduce the cost of financing, the number of rich countries eventually improve the return on investment, poor countries won the capital accumulation, to achieve a winwin situation. Indirect channel refers to the positive external effect of capital account opening. For example, capital inflow of foreign direct investment will also bring technology spillover effect, bringing technology and management experience from developed countries to poor countries with scarce capital, promoting technological innovation in countries with scarce capital, and bringing better management system and macroeconomic order. At the same time, however, the actual flow of capital from developed to developing countries is far from what is predicted by neoclassical economic growth theory, which is called the "Lucas paradox", or even the "reverse flow of capital". Li Jun-jiang and Xu Zheng through the review and summary the United States, Japan and the three countries of Latin America's capital account opening process and conclusion, the discovery of capital account liberalization has a comparative advantage effect and multiplier effect and capital dependence harm, put forward only to maintain China's economic development speed, gradually formed the capital account needs of economic and institutional comparative advantage, will have to continue the premise condition of capital account liberalization, external capital to long-term investment in China has the confidence and enthusiasm, and not just looking for short-term speculation in China's capital market[1]. Zhang Ming believes that China has underestimated the potential risks of capital account opening. In view of the deteriorating international situation, China should open its capital account cautiously and gradually and controllably, otherwise it may suffer from the outbreak of a systemic financial crisis [2].

In terms of empirical studies. Zhi Kun used the fact measure of capital account opening constructed by Lane and Milesi-Ferretti to study the sub-projects of capital account opening in low - and middle-income countries, and found that direct investment increased the growth rate of real GDP per capita, while portfolio investment and financial credit investment reduced the economic growth rate. Based on the panel data of 70 countries [3].Hu Yanan found that capital account opening has a threshold effect. When an economy fails to cross the threshold, it will have a negative impact on economic growth. After crossing the threshold, the relationship with economic growth is significantly positive [4].Lei Wenni and Jin Ying introduced the square term of capital account openness into the regression equation based on the data of 176 countries from 1980 to 2013, and found that with the improvement of capital account openness, the promoting effect on the economy turned from positive to negative. Her explanation is that economies in highly open environments are very sensitive to information, and unfettered capital flows increase vulnerability, when unstable factors are not conducive to economic growth [5]. Xiong Yanfei, Lu Jun et al. studied the impact on economic fluctuations. The impact of international capital inflow and outflow on per capita consumption growth rate and per capita real GDP growth rate fluctuations of developing countries was significantly higher than that of OECD countries [6].

Through literature reading, it is found that many scholars have studied the opening of the capital account from various aspects and perspectives, but there is still a great controversy over the economic consequences of the opening of the capital account. In this regard, this paper collates the macroeconomic data of 74 countries from 1990 to 2017 , and studies the country effect and nonlinear effect of capital account opening on economic growth using the systematic GMM estimation method.

\section{The empirical analysis}

\subsection{Econometric model setting}

Based on the neoclassical growth model and referring to the literature of Barro(1991) and Hu Yanan et al. (2019), the regression model formula is constructed in this paper as follows:

Growth $_{i t}=\beta_{1} \ln$ gdp $_{i t-1}+\beta_{2}$ kaopen $_{i t}+\beta_{3}$ school $_{i t}+$ $\beta_{4}$ invest $_{i t}+\beta_{5}$ life $_{i t}+\beta_{6}$ pop $_{i t}+\alpha_{i}+\varepsilon_{i t}$

Where i stands for country and t for year.Growth ${ }_{i t}$ It's the explained variable, it's the GDP growth rate.kaopen it $_{\text {. }}$ Is the core explanatory variable, indicating the degree of capital account opening. Control variables include: represents the initial per capita income level, represented by the logarithm of the per capita real GDP in the initial period; $\ln g d p_{i t-1}$ school $_{i t}$ Represents the level of education, represented by the gross enrollment rate of 
middle schools; invest $_{i t}$ Represents the level of investment, expressed as the proportion of total capital formation to GDP; lif $e_{i t}$ Is life expectancy, expressed in terms of life expectancy; op $_{i t}$ Represents the rate of population growth, expressed as the annual rate of population growth. $\alpha_{i}$ Is the individual fixed effect, and $\varepsilon_{i t}$ is the random disturbance term.

SinceGrowth ${ }_{i t}=\ln g d p_{i t}-\ln g d p_{i t-1}$ after substituting equation (1), equation (1) can be rewritten into the following equivalent form and used as the following econometric model:

$\ln g d p_{i t}=\beta_{1} \ln g d p_{i t-1}+\beta_{2}$ kaopen $_{i t}+\beta_{3}$ school $_{i t}+$ $\beta_{4}$ invest $_{i t}+\beta_{5}$ life $_{i t}+\beta_{6}$ pop $_{i t}+\alpha_{i}+\varepsilon_{i t}$

It can be seen from the above equation that we use a dynamic panel data model. If the traditional OLS method is used for estimation, the estimated coefficients will be inconsistent. In addition, the study on the impact of a country's capital account opening on economic growth may have a big endogenous problem, because economic growth may also affect the further development of the capital account, leading to a two-way causal relationship. In addition, other factors may also have a common impact. Therefore, the generalized moment estimation (system GMM) method can overcome this shortcoming and obtain a consistent estimator.

\subsection{Data Interpretation}

The variables used in this section, including GDP growth rate, per capita GDP, total capital formation as a percentage of GDP, population growth rate, gross secondary school enrollment rate, and life expectancy, are all from the World bank's WDI database (World Development Indicators).In order to avoid the influence of data outliers on the empirical results, we deleted countries with data missing, small countries, and non-single country economies, and finally obtained the transnational panel data composed of data from 74 countries from 1990 to 2017.

There are two ways to measure the openness of capital account, one is the legal measure, and the other is the fact measure. The indicator of legal capital account openness comes from the information provided by the IMF's AREAER. AREAER publishes the information on the capital account control of IMF member countries, and USES 0 and 1 to represent the non-opening and opening of the capital account, respectively. This binary measurement is obviously too crude. Chinn \& Ito (2006,2008) revised this index, believing that the score should not only consider capital account control, but also other factors that may affect capital flow, such as current account control and related exchange rate settlement policies. Based on the above, Chinn \& Ito takes into account the existence of multiple exchange rates, the degree of current account control, the degree of capital account opening, and whether there is a requirement to turn in export income. It is concluded that the index kaopen of capital account opening is distributed between $-1.83-2.50$. The higher the value, the higher the degree of capital opening is. The index looks at the breadth and intensity of capital controls, as well as the number of 182 countries, the time span 1970 to 2017 and the number of updates. Based on the research purpose of this paper and a comprehensive consideration of the applicability and availability of each measurement method, this paper adopts the kaopen index of Chinn \& Ito $(2006,2008)$ to measure the degree of capital account openness.

\subsection{The empirical results}

\subsubsection{Descriptive statistics}

According to the index of capital account openness published by Chinn\&Ito until 2017, combined with the availability of overall data, this paper selects panel data of 74 countries with a total sample from 1991 to 2017.In order to further consider whether there is heterogeneity among different countries, according to the world bank division, in this paper, those with per capita GDP greater than us $\$ 12,475$ in 2012 are classified as high-income countries, while those with per capita GDP less than us $\$ 12,475$ are classified as low - and middle-income countries. Descriptive statistical results are shown in table 1 below.

Table1. Descriptive Statistics

\begin{tabular}{|l|c|c|c|c|c|}
\hline VARIABLES & N & mean & sd & min & max \\
\hline ln_gdp & 1998 & 8.894 & 1.473 & 5.761 & 11.42 \\
\hline kaopen & 1998 & 0.560 & 1.589 & -1.917 & 2.347 \\
\hline school & 1998 & 79.38 & 29.75 & 6.320 & 156.6 \\
\hline ivest & 1998 & 23.66 & 7.587 & -3.740 & 70.66 \\
\hline life & 1998 & 71.34 & 8.943 & 42.52 & 84.10 \\
\hline pop & 1998 & 1.541 & 1.471 & -3.100 & 17.51 \\
\hline $\begin{array}{l}\text { Number of } \\
\text { code }\end{array}$ & 74 & 74 & 74 & 74 & 74 \\
\hline
\end{tabular}

\subsubsection{Regression results}

The following table shows the regression results using the systematic GMM method, table 2 shows the regression results of the whole sample countries, and table 3 shows the grouping regression results of high-income and low and middle-income countries after considering the country differences.

Table2. Full Sample Regress

\begin{tabular}{|l|c|c|}
\hline VARIABLES & In_gdp & In_gdp \\
\hline kaopen & $0.0067^{* * *}$ & $0.0060^{* * *}$ \\
& $(15.87)$ & $(18.89)$ \\
\hline L.Ingdp & $0.9745^{* * *}$ & $0.9763^{* * *}$ \\
& $(898.33)$ & $(228.56)$ \\
\hline school & & $0.0003^{* * *}$ \\
& & $(13.87)$ \\
\hline ivest & & $0.0026^{* * *}$ \\
& & $(31.86)$ \\
\hline life & & $-0.0009^{* * *}$ \\
& & $(-3.27)$ \\
\hline pop & & $-0.0082^{* * *}$ \\
& & $(-32.86)$ \\
\hline Constant & $0.2419^{* * *}$ & $0.2143^{* * *}$ \\
& $(24.19)$ & $(9.46)$ \\
\hline AR1 & 0.0000 & 0.0000 \\
\hline
\end{tabular}




\begin{tabular}{|l|c|c|}
\hline AR2 & 0.0720 & 0.0773 \\
\hline sargan & 1.0000 & 1.0000 \\
\hline Observations & 1,924 & 1,924 \\
\hline Number of code & 74 & 74 \\
\hline \multicolumn{2}{|c|}{$Z$ statistics in parentheses ${ }^{* * *} \mathrm{p}<0.01,{ }^{* *} \mathrm{p}<0.05,{ }^{*} \mathrm{p}<0.1$} \\
\hline
\end{tabular}

Table3. Grouping Regression

\begin{tabular}{|l|c|c|}
\hline & High income group & $\begin{array}{c}\text { Low and middle } \\
\text { income group }\end{array}$ \\
\hline VARIABLES & In_gdp & In_gdp \\
\hline kaopen & $0.0067^{* * *}$ & 0.0000 \\
& $(4.49)$ & $(0.02)$ \\
\hline L.lngdp & $0.9271^{* * *}$ & $0.9764^{* * *}$ \\
& $(69.62)$ & $(90.96)$ \\
\hline school & $0.0009^{* * *}$ & 0.0001 \\
& $(6.83)$ & $(1.15)$ \\
\hline ivest & $0.0042^{* * *}$ & $0.0017^{* * *}$ \\
& $(18.27)$ & $(14.57)$ \\
\hline life & 0.0009 & 0.0009 \\
& $(0.75)$ & $(1.01)$ \\
\hline pop & $-0.0057^{* * *}$ & $-0.0174^{* * *}$ \\
& $(-14.51)$ & $(-18.05)$ \\
\hline Constant & $0.4986^{* * *}$ & $0.1362^{* * *}$ \\
& $(9.97)$ & $(3.97)$ \\
\hline AR1 & 0.0018 & 0.0004 \\
\hline AR2 & 0.1113 & 0.3857 \\
\hline sargan & 1.0000 & 1.0000 \\
\hline Observations & 832 & 1,092 \\
\hline Number of & 32 & 42 \\
code & & \\
\hline \multicolumn{2}{|c|}{ Z statistics in parentheses $* * * \mathrm{p}<0.01, * * \mathrm{p}<0.05, * \mathrm{p}<0.1$} \\
\hline
\end{tabular}

It can be seen that the coefficient of capital account openness to economic growth in the whole sample is positive and passes the significance test at the level of $1 \%$.After considering the differences among countries, it is found that the capital account opening of high-income countries is still significant for economic growth at $1 \%$.However, for low - and middle-income countries, the impact of capital account opening on economic growth is not significant, either economically or statistically. This shows that high-income countries have achieved the dividend of opening up, while for low - and middleincome countries, there is no significant relationship between opening up the capital account and economic growth. This also tells us that for low - and middle-income countries, capital account opening should be more cautious and gradual. Based on the above regression results, it is strongly demonstrated that there is intercountry heterogeneity in capital account opening. If the analysis is conducted in accordance with all countries, such inter-country heterogeneity will be ignored and inappropriate results and Suggestions will be obtained.

From the point of view of the control variables, the coefficients are generally in line with the theoretical expectation. The coefficient of initial income level is significantly positive and the coefficient value is less than 1 , which satisfies the "convergence effect" proposed by the neoclassical growth model, that is, a country with a lower per capita real GDP is more likely to have a higher economic growth rate when other conditions are the same. The coefficient of population growth is significantly negative, indicating that the increase of population will reduce the level of per capita income, which is consistent with the analysis of neoclassical growth theory. The coefficient of education level and investment level are both significantly positive, and the coefficient of investment is larger than the coefficient of education, indicating that investment can promote economic growth more. The coefficient of life expectancy is not significant, indicating that life expectancy has no obvious promoting effect on economic growth.

\section{Conclusion and revelation}

What is the relationship between capital account opening and economic growth? This paper summarizes the panel data of 74 countries from 1990 to 2017 and builds an empirical model to study this. In view of this, this paper draws the following conclusions: considering the full sample of 74 countries, the coefficient of capital account openness is significantly positive. Further, considering the national differences found that high income countries still significant positive coefficient of capital account openness, and coefficient of capital account openness in low-income countries on economic and statistical significance were not significant, indicating that in the process of open the capital account, mainly high-income countries made open dividends, while in low and middle-income countries and earnings in the capital account liberalization. This is probably because, on the one hand, capital account opening is conducive to diversifying risks, increasing financing channels, increasing the rate of return on capital, and strengthening institutional construction and enterprise innovation. On the other hand, opening up will also bring short-term capital speculation, exchange rate fluctuations and increase the difficulty of monetary policy regulation and other unstable factors. Compared with high-income countries, low and middle-income countries are relatively backward in institutional development and financial development, resulting in more negative effects of opening-up than positive ones.

In the index calculated by Chinn \& Ito, China's capital account opening level in 2017 was only -1.21 , which was at a relatively low level and inconsistent with China's status as the world's second largest economy. On May 7, 2020, the central bank issuing the "foreign institutional investors in securities and futures investment funds management stipulation", one of the biggest changes in allowing qualified investors choose remit money currency and timing and greatly simplifies the investment income of export formalities. These policies show that China's determination to further open its capital account to the outside world has not wavered. However, in the dividend to open capital account at the same time, under the impact of the turbulent political and economic environment abroad and in China under the background of economic growth is slowing, in order to avoid the capital account may lead to the crisis, Chinese government should sound the sub-project of the progressive opening capital account, perfect the domestic financial environment and regulation legal system construction, to strengthen the prudent supervision, establishing financial crisis warning, management and coping mechanisms, more positive and active response to crisis and risks of capital account liberalization. 


\section{References}

1. Li Junjiang, Xu Zheng. Investigation on the benefits of capital account opening and China's path choice [J/OL]. Contemporary economic research: 1-10 [2020-05-06].

2. Zhang Ming. China's capital account opening: behavioral logic and scenario analysis [J]. World economy and politics, 2016 (04) : 139-155 + 160.

3. Zhi Kun, Fu Hongqiao. Different types of capital account opening and economic growth: evidence from low - and middle-income countries [J]. Economic review, 2017 (04) : 73-89.

4. Hu Yanan. Research on threshold effect and path of capital account opening $[\mathrm{J}]$. World economic research, 2020 (01): 68-81 + 136 .

5. Lei Wenni, Jin Ying. Capital account opening and economic growth -- a study based on transnational panel data [J]. International finance research, 2017 (01) : 59-67.

6. Xiong Yanfei, Lu Jun, Chen zheng. Capital account opening and macroeconomic fluctuations [J]. Economics (quarterly), 2015,14 (04) : 1255-1276.

7. Barro R J.. Economic Growth in a Cross-Section of Countries $[\mathrm{J}]$. Quarterly Journal of Economics, 1991, 106( 2) : 407-443 .

8. Jia Qiuran. A review of financial opening measurement method and indicator system [J]. Economic review, 2011 (03) : 131-142. 